\title{
A TRANSFORMAÇÃO DA COMUNICAÇÃO TABAGISTA: UM ESTUDO DAS ESTRATÉGIAS DA MARCA MARLBORO
}

THE TRANSFORMATION OF TOBACCO COMMUNICATION: A STUDY OF MARLBORO BRAND STRATEGIES

\section{Bruna Benites Willagrand', Graziela Frainer Knoll ${ }^{2}$}

RECEBIDO EM: 22/02/2019 | ACEITO EM: 26/03/2019

DOI: $10.5902 / 2317175837030$

\section{RESUMO}

O objetivo deste trabalho é analisar as estratégias de comunicação utilizadas, desde 1924 até os dias atuais, pela marca Marlboro. Pretende-se identificar as estratégias de comunicação e os tipos de campanha adotados pela marca nesse período; verificar, com a elaboração de uma linha cronológica, as recorrências e mudanças ocorridas no conteúdo das campanhas publicitárias da marca; descrever quais aspectos da Lei Antifumo interferiram na campanha publicitária de cigarro e apontar as principais estratégias utilizadas desde então. Foram analisados conteúdo das mensagens, tipos de campanha e estratégias de comunicação em anúncios publicitários veiculados em revistas, no período de 1924 a 1998. Os resultados demonstram que a Marlboro utilizou várias estratégias de comunicação, porém a mais frequente foi a de posicionamento, e os tipos de campanha mais aplicados foram propaganda, lançamento e institucional. Como conclusão, o estudo apresenta a evolução da publicidade dessa marca tabagista que conseguiu se manter como a primeira no mercado.

Palavras-chave: Ciências Sociais Aplicadas; Comunicação; Publicidade; Estratégias.

1 Bacharel em Comunicação Social pela Universidade Franciscana.

2 Professora na Universidade Franciscana (UFN), no curso de Publicidade e Propaganda; Doutora em Letras - Estudos Linguísticos (Universidade Federal de Santa Maria - UFSM); Mestre em Letras - Estudos Linguísticos (UFSM); Especialista em Tecnologias da Informação e da Comunicação Aplicadas à Educação (UFSM); Bacharel em Comunicação Social, Publicidade e Propaganda (UFSM); Licenciada em Letras, Língua Portuguesa (UFSM). 
A TRANSFORMAÇÃO DA COMUNICAÇÃO TABAGISTA:

UM ESTUDO DAS ESTRATÉGIAS DA MARCA MARLBORO

\begin{abstract}
The aim of this work is to analyze the advertising of the Marlboro brand from the year 1924 to the present day, in relation to the strategies used. It is intended: to identify the communication strategies and campaign types used by the brand in that period; to verify the recurrences and changes occurred in the content of the advertising campaigns of the brand in the period, with the elaboration of a chronological line; describe what aspects of the Anti-Smoking Law interfered in the cigarette advertising campaign and identify the main strategies used since then. The content of messages, campaign types and communication strategies in branded commercials published in magazines from 1924 to 1998 were analyzed. The results demonstrate that the brand used several communication strategies, but the most used was the positioning, and the campaign types most used by the brand were advertising, launch and institutional. In conclusion, the study presents the evolution of the advertising of this brand smoker that managed to remain as the first in the market.
\end{abstract}

Keywords: Applied Social Sciences; Communication; Advertising; Strategies.

\title{
1 Introdução
}

A indústria tabagista foi, durante muito tempo, um anunciante que investiu em estratégias de comunicação, pois fumar estava associado a diversas qualidades, como elegância e poder. O cinema recebia grandes investimentos, para que atores aparecessem fumando em filmes e, com isso, incentivassem o público a consumir o produto (LIMA, 2017).

Até os anos 1950, os anúncios veiculavam publicidades de cigarro em jornais e revistas, pois eram os meios disponíveis, o que aumentou a visibilidade ao cigarro. Como estratégia para melhorar sua autoimagem, as empresas buscaram aperfeiçoar o produto, e criaram os cigarros com filtro, com a intenção de parecerem "mais seguros". A partir desse momento, a indústria, mesmo passando por momentos de crise e recebendo críticas, desenvolveu-se até chegar ao ano de 2011, quando foi decretada a Lei Antifumo no Brasil por pressão da OMS. Essa medida baseia-se na defesa e preservação da saúde e limita bastante a indústria do tabaco, especialmente no que tange à divulgação dos produtos. O CONAR (Conselho Nacional de Auto-regulamentação Publicitária) já havia feito uma proibição às campanhas no ano de 2000.

Atualmente, percebem-se mudanças no mercado e na indústria tabagista diante das pressões e das regulamentações feitas pela sociedade e governos de diferentes países, em razão do efeito nocivo do fumo. As empresas dessa área investem em estratégias de modernização, e o fumo é considerado a indústria que mais gera lucro, segundo a OMS (Organização Mundial da Saúde), que classifica o Brasil como o segundo maior produtor de tabaco e o maior exportador do mundo (AGÊNCIA BRASIL, 2017), tendo como marca tabagista mais valiosa a Marlboro. O sucesso dessa empresa deu-se, em grande parte, por seus investimentos na área do marketing, como patrocínios da Fórmula 1, público-alvo jovem e forte presença em restaurantes e bares. 
Diante desse quadro atual, o objetivo geral deste trabalho ${ }^{3}$ é analisar as estratégias aplicadas pela marca Marlboro, desde o ano de 1924 até os dias atuais. Além disso, pretende-se identificar as estratégias de comunicação e os tipos de campanha utilizados pela marca nesse período; verificar as recorrências e mudanças ocorridas no conteúdo das campanhas publicitárias da marca no período citado, com a elaboração de uma linha cronológica; descrever quais aspectos da Lei Antifumo interferiram na campanha publicitária de cigarro e identificar quais as principais estratégias adotadas desde a implementação da lei.

Foram observados estudos relacionados à questão ética e os problemas de nocividade advindos do cigarro, dentre eles: o trabalho de Barroso (2001), que aborda aspectos jurídicos relacionados à publicidade desse segmento de produto a partir das noções de liberdade de expressão, direito à informação e riscos à saúde do consumidor; o artigo de Boeira (2006), que realiza uma análise dos diferentes atores sociais envolvidos na questão da indústria tabagista, incluindo sua comunicação e publicidade; e a análise de Renovato et al. (2009) sobre as imagens presentes nas embalagens de cigarro a partir da perspectiva dos estudos culturais. Com base na observação desses estudos, percebe-se que a comunicação tabagista já está em pauta há certo tempo, mesmo quando ainda estava isenta da maioria das restrições em comparação com os dias atuais.

Assim, a relevância desta pesquisa se sustenta a partir da observação de como a Lei Antifumo afetou a comunicação tabagista desde os anos 50 até hoje. A pesquisa é qualitativa, de nível descritivo, e como técnica foi realizada a análise de conteúdo, caracterizada por Bardin (2009) como uma técnica utilizada para interpretar a matéria em análise, nesse caso, notícias online sobre a Lei Antifumo, anúncios publicitários da marca Marlboro e o próprio site da marca produtora do cigarro. Quanto à interpretação, a análise de conteúdo passa pela síntese dos dados, fazendo uso de "procedimentos sistemáticos e objetivos de descrição do conteúdo das mensagens" (BARDIN, 2009, p. 51).

Foram selecionados 11 anúncios da marca Marlboro desenvolvidos entre 1924 e 1998 com base nos diferentes públicos-alvos da marca e no discurso proposto para cada um, além das adaptações que a Marlboro realizou para conseguir corresponder às exigências do período, pois a leitura prévia demonstrou que a marca realizou distintas abordagens. Como a publicidade de cigarros passou a ser proibida nas mídias a partir dos anos 2000, a análise incluiu o site internacional e brasileiro da marca Philip Morris, já que ali, como hipótese de pesquisa, continuam a ser utilizadas estratégias de comunicação que auxiliam na análise do contexto atual da marca. Para a complementação da pesquisa, foi criada uma linha do tempo que auxilia a compreender a evolução da publicidade tabagista ao longo dos anos, com foco na análise das estratégias utilizadas pela marca e seus tipos de campanha desde a década de 1924 até o ano 2018.

Os procedimentos de análise foram os seguintes: descrição do contexto com retrospectiva dos principais fatores históricos do anunciante no contexto 
da Lei Antifumo; descrição do contexto de comunicação da marca Marlboro, incluindo seu site; descrição dos anúncios em termos de conteúdo temático recorrente; identificação dos tipos de estratégias de comunicação (LUPETTI, 2002) e dos tipos de campanha (SAMPAIO, 2013); interpretação dos resultados a partir da teoria consultada.

\section{Comunicação integrada de marketing (CIM) e estratégias}

A comunicação é um dos itens do composto de marketing associados às decisões estratégicas que viabilizam a conquista do resultado esperado e, como afirma Vasconcelos (2009), ela tem a função de garantir que todo o planejamento, feito com base nas necessidades de determinado mercado, consiga alcançar o consumidor. Em relação ao marketing, Vasconcelos (2009) o define como um processo que orienta a empresa a atender às necessidades e aos desejos de determinado segmento de mercado, ainda acrescenta que, é necessário determinar o mix de marketing ideal através das características do produto, preço, escolha dos pontos de venda e formas de distribuição e como será a promoção do produto, ou seja, sua comunicação. Por definição, "marketing é o processo de planejar e executar a concepção, estabelecimento de preços, promoção e distribuição de ideias, bens e serviços, para criar trocas que satisfaçam objetivos individuais e organizacionais" (American Marketing Association apud YANAZE, 2006, p. 8).

O processo de gerenciamento de marketing, conforme Ogden e Crescitelli (2007), é uma sequência de fases que devem ser definidas de forma objetiva, trabalhado para assegurar que todas as funções resultem em um planejamento eficaz e de qualidade. Cada fase depende da outra, por exemplo, a segunda fase depende de informações e direcionamento obtidos na primeira, já a terceira fase dependerá da segunda e da primeira, e assim por diante, até chegar ao objetivo final. É possível observar que as variáveis do macroambiente, que, segundo Kotler e Keller (2006), consistem em forças sociais maiores que afetam todo o microambiente (por exemplo, forças demográficas, econômicas, naturais, tecnológicas, políticas e culturais) interferem no plano de marketing e, pelo fato de a comunicação estar contida nele, acabam influenciando também o processo de comunicação. Um exemplo que pode ilustrar essa situação é a lei que restringiu a divulgação de cigarros nos pontos-devenda, medida que afetou o processo de divulgação dos fabricantes. Ogden e Crescitelli (2007) ainda afirmam que a comunicação integrada de marketing é uma das variáveis do mix de marketing, já que demonstra a importância de comunicar a mesma mensagem para os mercados-alvos e pode ser entendida como uma evolução do processo de comunicação, adaptado conforme as mudanças do ambiente. As ferramentas da CIM são compostas por diversas formas de comunicação, as quais são, segundo os autores: propaganda, promoção de vendas, marketing direto, marketing digital, venda pessoal, relações 
públicas, publicidade, eventos e experiências. Cada uma dessas variáveis afeta o programa de marketing como um todo, de modo que, para garantir sua eficácia, todas devem ser gerenciadas.

A partir de cada variável, será desenvolvida uma estratégia para suas funções, e essa deve ser coerente com a estratégia geral. Por exemplo, a área da publicidade deve desenvolver um plano de acordo com sua função, porém ele deve ser pensado de modo que complemente e seja coerente com as outras áreas que estão inclusas, como relações públicas e marketing digital, obtendo uma CIM com resultados positivos, a fim de comunicarem de maneira homogênea a todos os envolvidos (desde os colaboradores, até os consumidores que precisam se sensibilizar). Assim, a integração de diferentes tipos de mídia e de contatos com diversos públicos, desde que se transmita a mesma mensagem central, é fator essencial para o bom desempenho da campanha e das estratégias utilizadas.

Por meio da comunicação integrada e estratégica, juntamente com o conhecimento das ações dos concorrentes, uma empresa consegue alcançar grande parte de seus objetivos. Nesse sentido, para Chandler (1963, p. 463), "a estratégia pode ser definida como a determinação das metas e dos objetivos básicos de longo prazo de uma organização e a adoção de cursos de ação e a alocação de recursos para realizar estas metas". Para definir os objetivos, devem-se usar diferentes estratégias, que podem ser utilizadas de maneira concomitante, com possibilidade de adaptação às mudanças. De acordo com Kotler e Keller (2006) não é fácil elaborar várias estratégias com coerência para uma empresa chegar ao seu objetivo, porém, com a rapidez de atuação dos mercados, é insustentável adotar uma estratégia única. Percebe-se que as empresas estão em uma concorrência acirrada e, por isso, para diferenciarem-se uma das outras, buscam estratagemas eficazes para se destacar dentro do mercado de trabalho, além de fortalecer as relações entre consumidores e marcas.

Segundo Tironi e Cavallo (2004), a comunicação estratégica é uma ferramenta utilizada por diferentes organizações, como entidades de governo, instituições religiosas, empresas, fundações, entre outras, que atua para fazer com que essas alcancem seus objetivos e, para isso acontecer, deve-se contar com uma visão que analise e compreenda o que rodeia a empresa e as diferentes situações que vivencia. Conforme Tironi e Cavallo (2004, p. 34), "a comunicação estratégica depende de terceiros atores, e isso depende da capacidade de interação pessoal, da compreensão dos critérios e, sobretudo, da argumentação". Além disso, funciona para que as organizações enfrentem as tentações e crises. Outra afirmação feita pelos autores é de que a comunicação estratégica também é conhecida como uma prática que opera antes da publicidade, na preparação de um briefing, que é uma etapa em que se define o que quer o anunciante, qual sua mensagem, a qual audiência quer chegar e o que deseja provocar, além da definição da solução criativa que a publicidade deve encontrar, do uso e da escolha adequada do meio de comunicação (TIRONI; CAVALLO, 2004). Em suma, as estratégias se fazem presentes no desenvolvimento da campanha e na 
evolução dos resultados: "Comunicação estratégica é a prática que tem como objetivo converter o vínculo das organizações com seu entorno cultural, social e político em uma relação harmoniosa e positiva desde o ponto de vista de seus interesses e objetivos" (TIRONI; CAVALLO, 2004, p. 33).

Para Oliveira e Paula (2007), a comunicação estratégica possui, pelo menos, dois aspectos relevantes: o primeiro se refere à coerência entre a comunicação e os objetivos e as estratégias de negócio e de gestão; o segundo diz respeito ao que se espera dos atores sociais nas decisões organizacionais. Nesse caso, conforme afirma Pérez (2012), a comunicação estratégica torna-se parte do atual cenário que precisa se manter, ainda que com alguns obstáculos, já que os meios de comunicação consideram que as organizações precisam de capacitação estratégica e de diálogo, pois, segundo o autor, a cada sete estratégias, cinco falham. Com isso, permanece a dúvida entre pesquisadores e professores: se a culpa disso seria da própria academia ou realmente do despreparo para enfrentar o novo contexto organizacional.

A empresa deve sempre pensar no caminho que desperte as avaliações positivas no público, mantendo a coerência da rede de mensagens destinadas a ele, para não haver falhas ou inconsistências. Nesse sentido, o quadro a seguir apresenta tipos de estratégias de comunicação que, segundo Lupetti (2002), podem ser utilizadas em campanhas publicitárias.

Quadro 1 - Estratégias de comunicação

\begin{tabular}{|c|c|}
\hline Tipo de Estratégia de Comunicação & Definição \\
\hline Estratégia de Informação & $\begin{array}{l}\text { Caracteriza-se pela prioridade dada à informação de um produto ou empresa. } \\
\text { É preciso informar a finalidade do produto, as vantagens e os benefícios. } \\
\text { Costumeiramente utilizada no lançamento de um produto novo ou inédito. }\end{array}$ \\
\hline Estratégia Testemunhal & $\begin{array}{l}\text { É a apresentação de um testemunho que comprova a utilidade e/ou eficácia do } \\
\text { produto ou serviço. } 0 \text { uso de celebridades - atores e atrizes consagrados - podem } \\
\text { trazer um bom retorno à campanha publicitária. }\end{array}$ \\
\hline Estratégia de Comparação & $\begin{array}{l}\text { Sem utilizar estratégias agressivas ou ataques, compara seu produto ao de seu } \\
\text { concorrente, porém não ataca o concorrente. }\end{array}$ \\
\hline Estratégia de Humor & $\begin{array}{l}\text { Como o próprio nome sugere, apela para o humor ao apresentar ou abordar um } \\
\text { produto. O uso de trocadilhos, piadas e sátiras é frequente quando utilizada essa } \\
\text { estratégia. }\end{array}$ \\
\hline Estratégia Ofensiva & $\begin{array}{l}\text { Compreende o ataque ao concorrente, tentando atingir suas vulnerabilidades. Para } \\
\text { utilizá-la de forma efetiva, é preciso conhecer muito bem o alvo do ataque, suas } \\
\text { fraquezas e potencialidades. Pode romper a ação da concorrência edeve mostrar o } \\
\text { lado frágil do concorrente. }\end{array}$ \\
\hline Estratégia de Defesa & $\begin{array}{l}\text { É uma estratégia de aproveitamento das forças empresariais, uma forma de repelir } \\
\text { um ataque. Normalmente utilizada pelos líderes de mercado, com grande posição } \\
\text { competitiva. }\end{array}$ \\
\hline Estratégia Indiferenciada & $\begin{array}{l}\text { O objetivo não é priorizar as vendas, mas a imagem da marca. É recomendada para } \\
\text { fixar marcas de empresas ou linhas de produtos. }\end{array}$ \\
\hline $\begin{array}{l}\text { Estratégia de Posicionamento ou } \\
\text { Reposicionamento }\end{array}$ & $\begin{array}{l}\text { Esta estratégia busca, de alguma forma, tornar o produto marcante para o } \\
\text { consumidor. Quando se consegue associar uma palavra à marca de seu produto, } \\
\text { dificilmente um concorrente poderá utilizá-la. }\end{array}$ \\
\hline
\end{tabular}


É importante ressaltar que, em uma mesma campanha publicitária, podem ser utilizadas mais de uma estratégia, ainda que uma possa ser mais proeminente do que as outras. Conforme as medidas adotadas, realizam-se diferentes tipos de campanhas publicitárias, investindo-se em conceitos e apelos que sejam adequados aos objetivos de comunicação.

\subsection{Campanha publicitária}

Uma campanha publicitária deve ser constituída por peças que mantenham a unidade para que seja possível aumentar seu impacto diante do público, pois, segundo Sampaio (2013), uma campanha é composta por várias peças em diferentes meios de comunicação, tanto meios massivos, quanto segmentados. Esses meios são explorados com base nos dados coletados a partir de pesquisas de mercado, com o objetivo de cumprir os objetivos de comunicação determinados pelo anunciante e definidos ou ajustados pelos profissionais de comunicação. Nesse sentido, Sampaio (2013) afirma que independentemente do público ao qual se destina a comunicação, um planejamento de ações é sempre necessário.

A campanha pode ser realizada através de um programa de comunicação interna e comunicação externa. No primeiro tipo, Brum (1994) defende a necessidade de valorizar e apoiar os funcionários e colaboradores, tendo como retorno o esforço deles para obter sucesso. Ainda segundo a autora, os servidores, ao perceberem que os superiores são partes integrantes do processo, compartilham mais suas ideias e opiniões por sentirem-se mais confiantes. Brum (1994) ainda afirma que a comunicação interna deve ser clara para que todos possam contribuir com os objetivos comuns e deve ser realizada entre todos os níveis da organização para tornar a equipe mais próxima. Já a comunicação externa tem como foco a opinião da sociedade, além de ser responsável pela imagem da empresa. Sampaio (2013) defende que campanhas de comunicação variam de acordo com o objetivo da comunicação e do público a ser alcançado, como também podem ser de vários tipos: institucional, de propaganda, guarda-chuva, de promoção, de promoção de vendas, de incentivo e cooperada.

Seguindo essa mesma classificação, Lupetti (2002, p. 112) explica: a "Campanha Institucional é aquela que divulga a empresa como um todo, é posicionar a imagem, informar seu segmento de atuação". No mesmo sentido, Sampaio (1999) afirma que esse tipo de campanha tem como objetivo obter melhorias na reputação da marca e que há também as institucionais de serviços públicos, que são realizadas por governo, entidades ou outros órgãos afins. Outro tipo é a campanha de propaganda, que para Sant'Anna (2009), cria a demanda para determinado serviço ou produto, podendo ainda ser realizada para divulgação de eventos. É comum ser utilizada nos lançamentos de produtos em que a necessidade de informações se faz presente. Já a campanha utilizada por empresas que possuem uma linha de produtos com modelos diferentes e por empresas que não têm marcas nominais em seus produtos é 
a do tipo guarda-chuva. Esse tipo é conhecido também, conforme Sampaio (2013), como campanha de linha de produtos, pois reúne características das campanhas institucional e de propaganda. Sobre a campanha de promoção, Sampaio (2013) afirma que é realizada por um período limitado e predeterminado, com o objetivo de gerar vendas rapidamente. Tem como ponto positivo a interatividade com o consumidor, pois procura solicitar uma ação, dando-lhe algum produto ou serviço em troca. Como exemplo é possível citar a campanha da Parmalat, lançada em 1996, em que os consumidores juntavam os códigos de barra dos produtos e trocavam por bichinhos de pelúcia, acelerando vendas (SAMPAIO, 1999).

A campanha de promoção de vendas, conforme Sampaio (2013), tem relação direta com a redução de preços, como liquidação, "compre 1 e leve 2", " $50 \%$ de desconto", brindes, entre outras, tendo como foco a diminuição dos estoques. Além disso, pode ser dirigida para o consumidor ou para os envolvidos no negócio, como revendedores, por exemplo. Com o objetivo de proporcionar uma melhoria na relação entre empresa, cliente e funcionários, além de incentivar as vendas, a campanha de incentivo, de acordo com Sampaio (2013), tem como público as pessoas que fazem parte da empresa. Nesse tipo de campanha, o foco não é a divulgação da marca, mas manter os funcionários motivados para atingir metas, por exemplo, vendendo mais para ganhar uma comissão. Ainda segundo Sampaio (2013), a campanha cooperada tem como principais características levar o consumidor ao ponto-de-venda e promover o "giro" dos produtos no local. É também conhecido como campanha de varejo, já que é típico das empresas de varejo que veiculam os produtos de seus fornecedores, ou seja, duas ou mais indústrias fazem uma parceria e dividem os custos de criação, produção e veiculação. Por exemplo, uma indústria de bebidas se compromete, por uma peça ou campanha publicitária, com um estabelecimento de refeições.

Para realizar qualquer um dos tipos de campanhas, é preciso que a mensagem chegue ao público de forma clara e eficiente. Nesse sentido, Cabral (1990, p. 49) afirma que "a publicidade atua por fatores acumulativos. É a quantidade que provoca uma nova qualidade, um novo posicionamento, gerando conceitos e formando tendências".

O posicionamento, por sua vez, segundo Correa (2004), é a imagem pela qual a marca gostaria de ser vista pelo público-alvo, ou seja, é por meio do posicionamento que se determina qual a mensagem a ser transmitida. Isso ocorre mediante a soma de três fatores: a promessa básica (o benefício do produto), a justificativa utilizada (o argumento) e os atributos complementares da imagem da marca. Tais fatores estão presentes na comunicação integrada de marketing e se evidenciam na campanha publicitária, com diferentes tipos de estratégias. 


\section{Análise das estratégias de Marlboro: do contexto aos anúncios}

O início da regulamentação da publicidade tabagista aconteceu no ano de 1988, quando as marcas de cigarro foram obrigadas a inserir a frase "O Ministério da Saúde adverte: fumar é prejudicial à saúde" nas embalagens dos produtos derivados do tabaco. Logo em 1990, a obrigatoriedade de frases de alerta passou a ser inserida em propagandas de rádio e televisão e, seis anos depois, comerciais de produtos tabagistas passam a ser veiculados apenas no horário entre $21 \mathrm{~h}$ e $6 \mathrm{~h}$, além de ser proibida a prática de fumar em locais fechados, a não ser em fumódromos (ANVISA, 2012).

Em 2000, a propaganda tabagista em revistas, jornais, outdoors, televisão e rádios passou a ser proibida também, juntamente com patrocínios e eventos culturais e esportivos associados ao cigarro, o que era muito utilizado nas décadas de 80 e 90 pela marca Marlboro. Um ano depois, em 2001, a Anvisa (Agência Nacional de Vigilância Sanitária) determinou a inserção obrigatória de imagens de advertência em material de propaganda e embalagens de produtos tabagistas. Já em 2003, as seguintes frases passaram a ser incluídas nas embalagens dos produtos: "Venda proibida a menores de 18 anos" e "Este produto contém mais de 4.700 substâncias tóxicas, e nicotina que causa dependência física ou psíquica. Não existem níveis seguros para consumo destas substâncias" (ARAUJO, 2014).

Em 2011, a Lei Antifumo foi decretada, proibindo o consumo de produtos fumígenos em locais de uso coletivo, públicos ou privados, além de extinguir fumódromos e proibir a propaganda comercial tabagista até mesmo nos pontos de venda, permitindo somente a exposição dos produtos acompanhados por mensagens sobre os malefícios provocados pelo fumo. Observam-se as seguintes mudanças após a regulamentação imposta em 2011 (Quadro 2):

Quadro 2 - Regulamentação dos anúncios

\begin{tabular}{|l|l||}
\hline ANTES DA REGULAMENTAÇÃO & DEPOIS DA REGULAMENTAÇÃO \\
\hline $\begin{array}{l}\text { Não havia definição sobre o que poderia ser considerado } \\
\text { local coletivo fechado, onde é proibido fumar. }\end{array}$ & $\begin{array}{l}\text { O fumo é proibido em locais fechados de uso coletivo, mesmo que total } \\
\text { ou parcialmente fechado em qualquer de seus lados, por uma parede, } \\
\text { divisória, teto, toldo ou telhado. }\end{array}$ \\
\hline $\begin{array}{l}\text { Permitia áreas para fumantes ou fumódromos em } \\
\text { ambientes fechados, públicos ou privados. }\end{array}$ & $\begin{array}{l}\text { O fumo, em qualquer circunstância, está proibido em local coletivo } \\
\text { fechado, abolindo áreas para fumantes ou fumódromos. }\end{array}$ \\
\hline Não estabelecia condições para comercialização. & $\begin{array}{l}\text { Os produtos devem ficar expostos no interior do estabelecimento } \\
\text { comercial e 20\% do mostruário visível ao público, devem ser ocupados } \\
\text { por mensagens de advertências sobre os males do fumo, a proibição da } \\
\text { venda a menores de 18 anos e a tabela de preços. }\end{array}$ \\
\hline \hline $\begin{array}{l}\text { Eram permitidas propagandas comerciais de produtos } \\
\text { fumígenos no display. }\end{array}$ & $\begin{array}{l}\text { Fica proibida a propaganda comercial de produtos fumígenos em todo } \\
\text { o território nacional. Apenas a exposição dos produtos nos locais de } \\
\text { vendas é permitida. }\end{array}$ \\
\hline
\end{tabular}


A TRANSFORMAÇÃO DA COMUNICAÇÃO TABAGISTA: UM ESTUDO DAS ESTRATÉGIAS DA MARCA MARLBORO

\begin{tabular}{|c|c|}
\hline $\begin{array}{l}\text { Não fazia referência às situações de exceção com relação } \\
\text { a cultos religiosos, locais de venda, em tratamentos de } \\
\text { saúde, produções artísticas e pesquisa. }\end{array}$ & $\begin{array}{l}\text { O fumo em lugares fechados é permitido em cinco situações, desde } \\
\text { que adotadas condições de isolamento, ventilação e exaustão do ar, } \\
\text { além de medidas de proteção ao trabalhador exposto: } \\
\text { - Em cultos religiosos caso faça parte do ritual; } \\
\text { - Em tabacarias sinalizadas; } \\
\text { - Em estúdios e locais de filmagem quando necessário à produção da } \\
\text { obra; } \\
\text { - Em locais destinados à pesquisa e ao desenvolvimento de produtos } \\
\text { fumígenos; } \\
\text { - Instituições de tratamento de saúde que tenham pacientes } \\
\text { autorizados a fumar pelo médico que os atende. }\end{array}$ \\
\hline $\begin{array}{l}\text { Estabelecia que as embalagens deveriam conter } \\
\text { advertências, especificamente em uma das laterais dos } \\
\text { maços, carteiras ou pacotes. }\end{array}$ & $\begin{array}{l}\text { As embalagens devem ter mensagens de advertência em } 100 \% \text { da face } \\
\text { posterior das embalagens e de uma de suas laterais. E a partir de } 2016 \text {, } \\
\text { foi incluído texto de advertência adicional sobre os malefícios do fumo } \\
\text { em 30\% da parte frontal das embalagens. }\end{array}$ \\
\hline
\end{tabular}

Fonte: Adaptado do Portal da Saúde. Disponível em: <http://www.brasil.gov.br/saude/2014/05/ministerio-da-saude-regulamenta-lei-antifumo-no-diamundial-sem-tabaco>. Acesso em: 20 nov. 2018.

A marca Marlboro foi originalmente lançada em 1847, em Londres, por Philip Morris e naquele momento, era voltada para mulheres, pois iniciou com a produção de cigarros com filtro, os quais eram rotulados como "femininos" por serem considerados teoricamente mais fracos, além de utilizar-se de mensagens publicitárias direcionadas para as mulheres, como "Uma extremidade cor de cereja para os seus lábios cor de rubi" (a cherry tip for your red ruby lips). Durante a Segunda Guerra Mundial, a marca foi retirada temporariamente do mercado e depois, com o término do conflito, outras marcas tabagistas acabaram sendo inseridas, como Camel e LuckyStrike, fazendo com que a marca Marlboro perdesse seu lugar privilegiado por um período de tempo. Porém, a Marlboro utilizou estratégias para conseguir reconquistar o mercado com o apelo dos cigarros com filtros, antes direcionados apenas para mulheres, divulgados como algo menos nocivo para a saúde, já que nesse mesmo período foi publicado pela revista Reader's Digest que o produto era causador do câncer de pulmão. Assim, o cigarro com filtro passou a ter como público-alvo, também, os homens (MUNDO DAS MARCAS, 2006).

A partir desse ponto, a marca percebeu um aumento nas vendas e passou a direcionar seu produto e estratégias para o público masculino. Em 1955, lançou a campanha "Tattooed Man", que fez uso de homens tatuados, atletas, pilotos, caubóis, entre outros, com a intenção de passar sensações como liberdade e coragem. Com essa campanha, deu um salto nas vendas, tendo como maior garoto-propaganda da história tabagista o caubói, que se tornou ícone na publicidade. Já no período de 1964, foi ao ar a campanha "Come to where the flavor is. Come to Marlboro Country", e, em 1970, a marca estava em terceiro lugar como a mais popular dos Estados Unidos, com isso, apenas dois anos depois, se tornou a marca mais vendida no mundo (BONA; BEAUMORD, 2010). Na mesma década, o ator que representava o caubói, David McLean, faleceu diagnosticado com câncer de pulmão. Com medo de o público associar sua morte ao cigarro, a marca mudou o foco por volta de 1978, procurando 
se inserir no mundo automobilístico, tornando-se parceira da Fórmula 1, das escuderias MacLaren, Penske e Ferrari.

O acordo com a Ferrari continua atualmente, porém, com a Lei Antifumo decretada em 2011, não é mais possível exibir os logotipos no carro, por causa da proibição de patrocínios diretos do cigarro, mas a Ferrari ainda é associada à marca tabagista por suas cores vermelha e branca. A Marlboro se mantém no topo, mesmo com novas regulamentações, principalmente com as embalagens de cigarro, que devem conter no seu verso o alerta sobre os malefícios do cigarro e apresentar conceitos como "sofrimento, infarto, perigo, produto tóxico e morte", seguida de imagens chocantes que retratam o problema (FOLHA DE SÃO PAULO, 2017).

Dessa forma, a publicidade tabagista se mantém por meio de estratégias indiretas para alcançar o público-alvo. Entretanto, a Marlboro continua líder no mercado americano, e uma das formas de a marca estabelecer seu posicionamento no mercado tem sido a comunicação realizada em seu site. Em $1997^{4}$, o site da Philip Morris International não apresentava nada relacionado com o nome Marlboro, nem Philip Morris, apenas a sigla PMI (Philip Morris International). O seu único conteúdo era a home page com a logo da empresa e informações, como telefone e endereço. Já em 2010, a marca passou a apresentar conteúdo informativo sobre os produtos e sobre a Philip Morris em si, além de começar a abordar a ideia de natureza, com a inserção da imagem de uma plantação de tabaco no cabeçalho do site. Também em 2010, passou a conter um menu com links sobre os produtos oferecidos pela marca, regulação do tabaco, entre outros.

No ano de 2014, a marca trabalhava no site a iniciativa de diminuir os danos causados pela fabricação do produto na Itália, com o uso de imagem humana e do próprio produto. Além disso, nos itens do menu, foi acrescentado um tópico sobre Sustentabilidade, no qual estavam presentes assuntos, como clima, agricultura e comunidades rurais. Em 2017, a Philip Morris Brasil passou a ser uma seção do Portal Mundial da marca, além de ter o site atualizado e voltado totalmente para o assunto Sustentabilidade, afirmando que a empresa apoia a iniciativa de um mundo mais sustentável, que preza pela natureza e pela diminuição do consumo do tabaco. Também mostra em seu site produtos fabricados pela empresa que não possuem tabaco, apontando as vantagens de consumi-los.

No mesmo menu de Sustentabilidade, a marca trabalha com a estratégia informativa ao detalhar os problemas que a queima do tabaco causa, a função da nicotina e a demanda por alternativas menos prejudiciais. O site de 2017 (Figura 1) apresenta também matérias afirmando que a empresa respeita os direitos trabalhistas em fazendas, é comprometida com a sustentabilidade do lugar onde opera, projeta um futuro livre do fumo e protege o ecossistema das fazendas. Além disso, a marca faz uso da estratégia de comparação ao ci- 
A TRANSFORMAÇÃO DA COMUNICAÇÃO TABAGISTA:

UM ESTUDO DAS ESTRATÉGIAS DA MARCA MARLBORO

tar em seu site que a empresa é líder mundial na fabricação de tabaco, ou seja, é a primeira em relação às outras marcas.

Figura 1 - Site, seção geral (1) e seção do produtor (2)

(1)

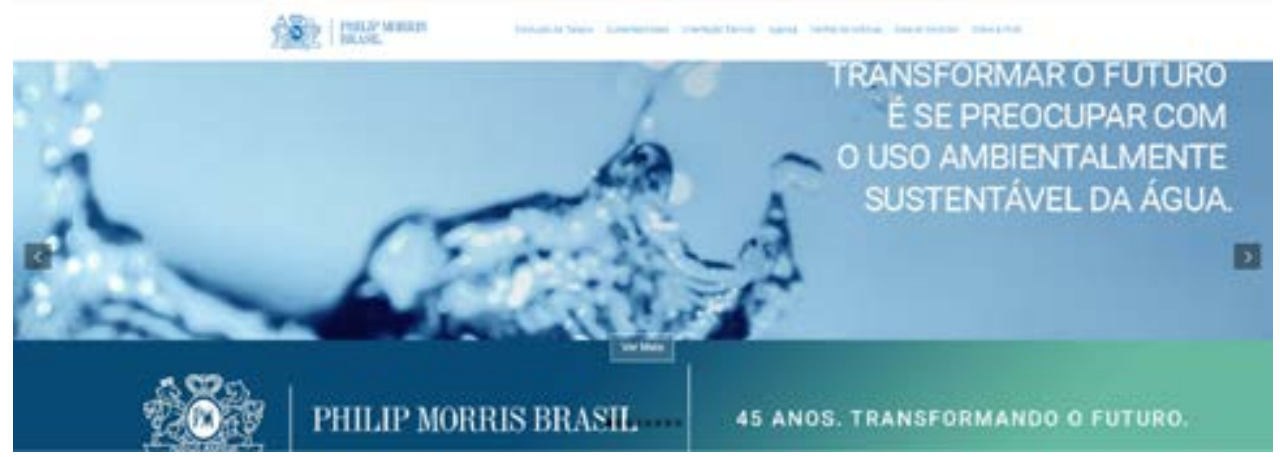

(2)
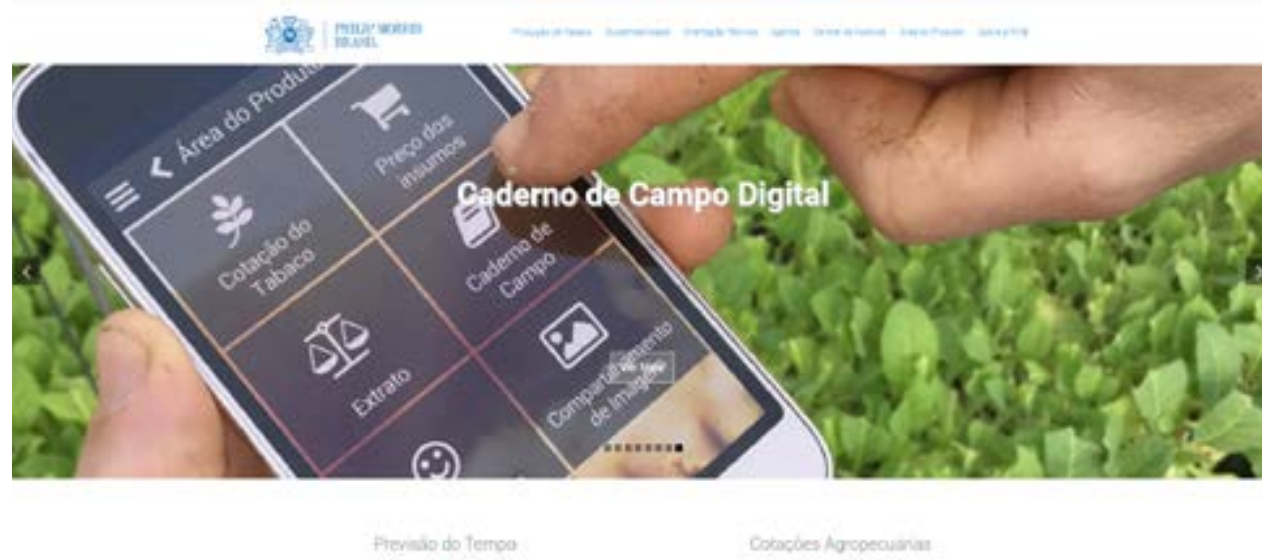

Cosacbes Arspecusunat

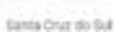

Fonte: Site da marca. Disponivel em: <https://www.produtorphilipmorris.com.br/>. Acesso em: 17 mar. 2018.

Ainda em 2017, o site passou a apresentar um espaço próprio para o produtor de tabaco, com informações como: a origem do tabaco, as fases de produção, os benefícios, cadastro ambiental rural, reflorestamento, produção de mudas, cotação do tabaco e de insumos, entre outros. O apelo fica evidenciado com a chamada "Transformar o futuro é se preocupar com o uso ambientalmente sustentável da água" e a imagem da água sobre fundo azul reforçando o apelo. Esses elementos presentes na comunicação resultam em um foco não mais no cigarro nos seus enunciados, ao mesmo tempo em que chama atenção para outros problemas socialmente relevantes, como a sustentabilidade.

\subsection{Apresentação dos resultados e discussão}


A partir da pré-análise do conteúdo dos anúncios de revista da marca, é possível identificar que as peças podem ser agrupadas em quatro eixos temáticos recorrentes: ideal feminino, humor e situação cotidiana, ideal masculino e esportes. Os anúncios estão identificados por códigos. No eixo do ideal feminino, eram exploradas figuras públicas femininas, como as divas do cinema, a exemplo do anúncio A1. No eixo de humor e situação cotidiana, eram abordados diálogos entre mãe e bebê, com a criança ciente da importância do cigarro para sua mãe, a exemplo do anúncio $A 2$. Já no terceiro eixo, o ideal masculino predominava, como nos anúncios $A 3, A 4, A 5, A 6, A 7, A 8, A 9, A 10$ e $A 11$, todos fazendo uso de imagens masculinas, a maioria explorando a figura do caubói, com a marca sendo representada durante anos pelo Marlboro Man. Ainda no terceiro eixo, destacam-se os anúncios que exploravam o estilo de vida rural, com cenas da lida no campo e imagens de cavalos, juntamente com os caubóis. Já no quarto eixo, foi explorada a temática de esportes, presente em A11, um anúncio de 3 páginas que aborda um campeonato de veloterra proporcionado pela marca o Marlboro Adventure Team (Figura 2). 
A TRANSFORMAÇÃO DA COMUNICAÇÃO TABAGISTA:

UM ESTUDO DAS ESTRATÉGIAS DA MARCA MARLBORO

Figura 2 - Exemplares analisados

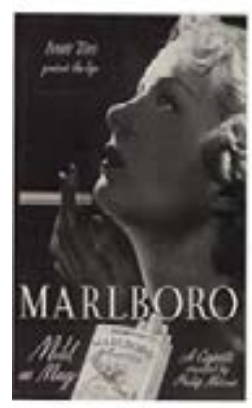

A1

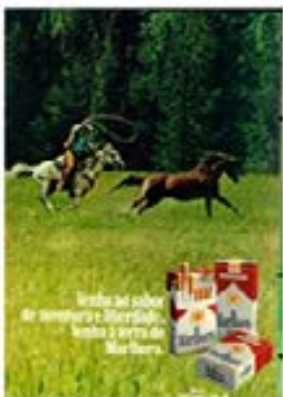

A5

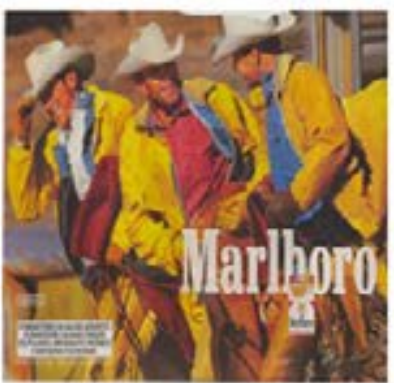

A9

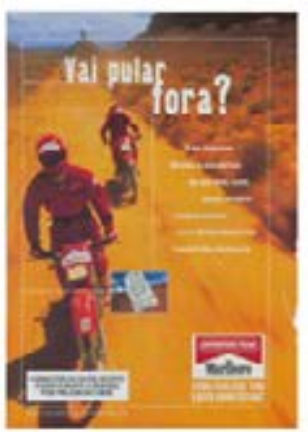

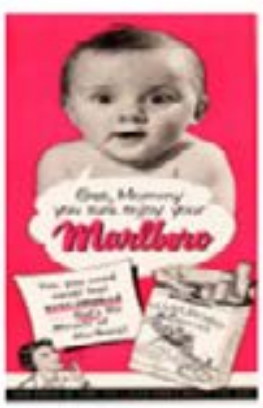

A2

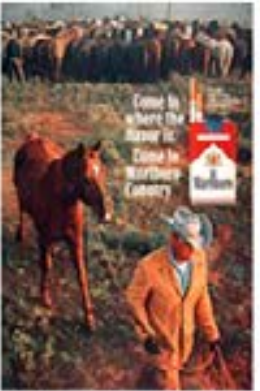

A3

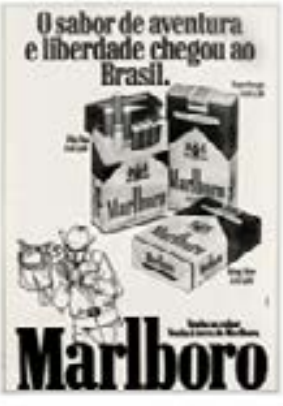

A4
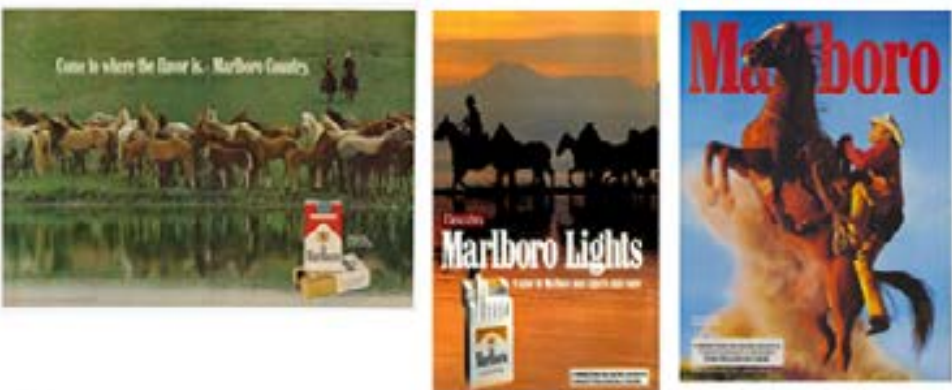

A6

A7

A8

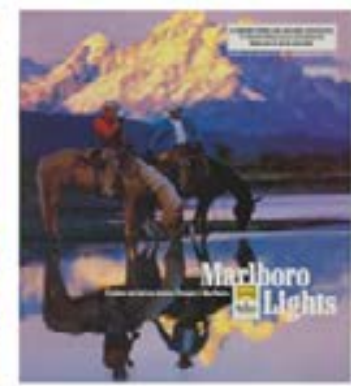

A10
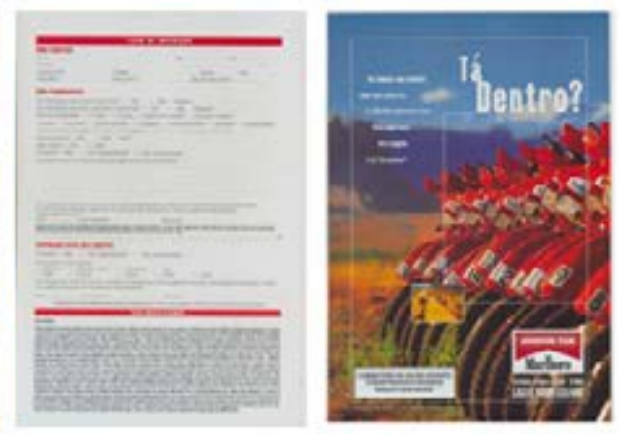

A11 (anùncio de 3 pagginas)

Fonte: Propagandas Históricas e Propaganda em Revista. Disponível em: <http://www.propagandaemrevista.com.br/ produtos/6/cigarros/>. Acesso em: 10 mar. 2018. 
Passando à identificação das estratégias e dos tipos de campanha de cada anúncio, elaborou-se o Quadro 3.

Quadro 3 - Estratégias e tipos de campanha

\begin{tabular}{|c|c|c|c|c|}
\hline v & Ano & Texto Verbal (original e tradução) & $\begin{array}{l}\text { Estratégias de } \\
\text { Comunicação (LUPETTI, } \\
\text { 2002) }\end{array}$ & $\begin{array}{l}\text { Tipos de Campanha } \\
\text { (SAMPAIO, 2013) }\end{array}$ \\
\hline A1 & 1924 & $\begin{array}{l}\text { "Ivory tips - protect the lips" } \\
\text { "Marlboro. A cigarette created by Philip Morris" } \\
\text { "Mild as May" } \\
\text { "Pontas de marfim - protege os lábios" } \\
\text { "Marlboro, o cigarro criado por Philip Morris" } \\
\text { "Leve como maio" }\end{array}$ & $\begin{array}{l}\text { Estratégia de Informação } \\
\text { Estratégia de } \\
\text { Posicionamento }\end{array}$ & Campanha de Propaganda \\
\hline$A 2$ & 1951 & $\begin{array}{l}\text { "Gee, Mommy, you sure enjoy your Marlboro". } \\
\text { "Yes, you need never feel over-smoked... that-s the Miracle } \\
\text { of Marlboro!" } \\
\text { "Mamãe, você certamente aproveita seu Marlboro" "Sim, } \\
\text { você nunca precisa sentir excesso de fumo... é o milagre de } \\
\text { Marlboro!". }\end{array}$ & Estratégia de Humor & Campanha de Propaganda \\
\hline A3 & 1964 & $\begin{array}{l}\text { "Come to where the flavor is. Come to Marlboro country." } \\
\text { "Venha para onde está o sabor. Venha para o mundo de } \\
\text { Marlboro" }\end{array}$ & $\begin{array}{l}\text { Estratégia de } \\
\text { Posicionamento }\end{array}$ & $\begin{array}{l}\text { Campanha de Propaganda, } \\
\text { Campanha Institucional }\end{array}$ \\
\hline A4 & 1975 & $\begin{array}{l}\text { "O sabor de Aventura e Liberdade chegou ao Brasil." } \\
\text { "Venha ao sabor. Venha à Terra de Marlboro". }\end{array}$ & $\begin{array}{l}\text { Estratégia de Informação } \\
\text { Estratégia de } \\
\text { Posicionamento }\end{array}$ & $\begin{array}{l}\text { Campanha de Lançamento } \\
\text { Campanha de Propaganda }\end{array}$ \\
\hline A5 & 1976 & $\begin{array}{l}\text { "Venha ao sabor de aventura e liberdade. Venha à terra de } \\
\text { Marlboro". }\end{array}$ & \begin{tabular}{|l|} 
Estratégia de \\
Posicionamento
\end{tabular} & Campanha de Propaganda \\
\hline A6 & 1976 & $\begin{array}{l}\text { "Come where the flavor is. Marlboro Country". } \\
\text { "Venha para onde está o sabor. Terra de Marlboro". }\end{array}$ & $\begin{array}{l}\text { Estratégia de } \\
\text { Posicionamento }\end{array}$ & Campanha de Propaganda \\
\hline A7 & 1992 & $\begin{array}{l}\text { "Descubra Marlboro Lights. } 0 \text { sabor de Marlboro num } \\
\text { cigarro mais suave". }\end{array}$ & $\begin{array}{l}\text { Estratégia de informação } \\
\text { Estratégia de } \\
\text { Posicionamento }\end{array}$ & Campanha de Lançamento \\
\hline A8 & 1997 & "Marlboro" & \begin{tabular}{|l|} 
Estratégia de \\
Posicionamento
\end{tabular} & Campanha de Propaganda \\
\hline A9 & 1997 & "Marlboro" & \begin{tabular}{|l|} 
Estratégia de \\
Posicionamento \\
\end{tabular} & Campanha de Propaganda \\
\hline A10 & 1997 & $\begin{array}{l}\text { "Marlboro Lights. } 0 \text { sabor em baixos teores. Porque é } \\
\text { Marlboro" }\end{array}$ & $\begin{array}{l}\text { Estratégia de } \\
\text { posicionamento e } \\
\text { Informação }\end{array}$ & Campanha de Lançamento \\
\hline A11 & 1998 & $\begin{array}{l}\text { [página 1] } \\
\text { "Vai pular fora? } 10 \text { dias atravessando } 600 \text { milhas no oeste } \\
\text { americano com jipes, motos, cavalos, descendo corredeiras } \\
\text { e escalando montanhas. Esse é o Marlboro Adventure Team. } \\
\text { Tá dentro? Então, inscreva-se já." } \\
\text { "Adventure Team Marlboro. Venha para esse time. Ligue } \\
0800555667 \text { ". } \\
\text { [página 2] ficha de inscrição } \\
\text { [página 3] } \\
\text { "Tá dentro? Vai começar uma aventura como você nunca } \\
\text { viu. É o Marlboro Adventure Team. Para saber mais vire a } \\
\text { página. E aí? Vai encarar?". } \\
\text { "Adventure Team Marlboro. Venha para esse time. Ligue } \\
0800555667 \text { ". }\end{array}$ & Estratégia de Informação & Campanha Institucional \\
\hline
\end{tabular}


De acordo com as estratégias de comunicação e com os tipos de campanha, percebe-se que as estratégias mais utilizadas nos anúncios são, em maior ocorrência, as de posicionamento, as de informação, em segundo lugar, e a estratégia de humor. Já sobre os tipos de campanhas, o mais utilizado foi o de propaganda, seguido da campanha de lançamento e, por fim, da campanha institucional. Fazendo a relação desses dados com as temáticas das propagandas, nos anúncios de ideal feminino, identificaram-se as estratégias de informação e posicionamento e campanha do tipo propaganda. Quanto ao eixo de humor e situação cotidiana, foi utilizada a estratégia de humor e a campanha de propaganda, com apresentação dos benefícios do produto citados por meio da fala do bebê. Já nos anúncios de ideal masculino, com a figura do caubói e o estilo de vida rural em evidência, prevaleceram as estratégias de posicionamento e de informação; e o tipo de campanha mais recorrente nesse eixo foi do tipo propaganda. No último eixo, no anúncio que trata de esportes, a estratégia encontrada foi de informação e o tipo de campanha foi institucional.

A partir do conceito de comunicação estratégica de Tironi e Cavallo (2004), os quais definem que essa é uma prática que inicia na preparação do briefing, constatou-se que a marca Marlboro, desde o início da década de 1920, definiu de forma pontual a mensagem que gostaria de transmitir e o que desejava provocar: inicialmente, explorou a imagem da mulher sexy e empoderada por consumir o produto, além da escolha do meio de comunicação adequado para chegar no público-alvo, isto é, naquele momento, as revistas. E, logo após, com o desenvolvimento das campanhas e a evolução dos resultados, foram envolvidas outras estratégias de comunicação, à medida que o público-alvo das campanhas também foi modificado e ampliado, visando, provavelmente, o aumento de vendas com a exploração da imagem do caubói em anúncios direcionados para o público masculino a partir dos anos de 1960.

Além disso, de acordo com a análise, em uma mesma campanha podem ser utilizadas várias estratégias, mesmo que uma seja mais proeminente do que as outras, pois ambas buscam alcançar as metas definidas pelo marketing, como por exemplo, a peça A1, de 1924, que faz uso das estratégias de informação e de posicionamento simultaneamente. Portanto, as campanhas, assim como as estratégias, podem ser de vários tipos e também podem ocorrer de forma simultânea, pois variam em função do objetivo da publicidade e do público a ser alcançado, conforme explicado por Sampaio (2013). Como exemplo, pode-se citar o anúncio $A 3$, o primeiro a conter caubói e vida rural, que utilizou os tipos de campanha de propaganda e institucional. Constata-se que nem sempre há uma relação de correspondência direta entre uma estratégia e um tipo de campanha, mas percebe-se, por meio dos anúncios analisados, que há algumas estratégias que se repetem para determinado tipo de campanha, como a estratégia de posicionamento combinada com campanha do tipo propaganda.

Sobre a Comunicação Integrada de Marketing, Ogden e Crescitelli (2007) 
destacam a importância de comunicar a mesma mensagem para os mercados -alvos, adaptando-a conforme as mudanças do ambiente. Enquanto isso, Vasconcellos (2009) ressalta a necessidade de entender as funções de marketing a partir do planejamento, sendo que, para isso, tem-se como primeiro passo encontrar a solução de um problema colhendo informações recentes, avaliando percepções e diagnosticando a situação do momento. Essa percepção ocorreu com a marca Marlboro, caso contrário, não haveria realizado tantos tipos de campanha e de comunicação estratégica diferentes ao longo dos anos.

Trata-se, também, de uma marca que soube explorar oportunidades de mercado, pois surgiu com o cigarro com filtro, direcionando sua publicidade para o público feminino, já que o produto era considerado "suave" demais para os homens. E, após uma revista famosa publicar, nos EUA, que o cigarro era causador do câncer de pulmão, e que o cigarro com filtro seria menos nocivo para a saúde, aproveitou para se reposicionar no mercado, ampliando o público-alvo do produto, não mais restrito ao público feminino. Além disso, a marca passou a explorar ainda mais as diversas formas de comunicação, como propaganda, patrocínios, eventos, marketing social, entre outras formas.

Para representar as mudanças ocorridas na evolução da comunicação estratégica da marca Marlboro, elaborou-se uma linha do tempo (Figura 3). 
A TRANSFORMAÇÃO DA COMUNICAÇÃO TABAGISTA:

UM ESTUDO DAS ESTRATÉGIAS DA MARCA MARLBORO

Figura 3 - Linha do tempo da marca

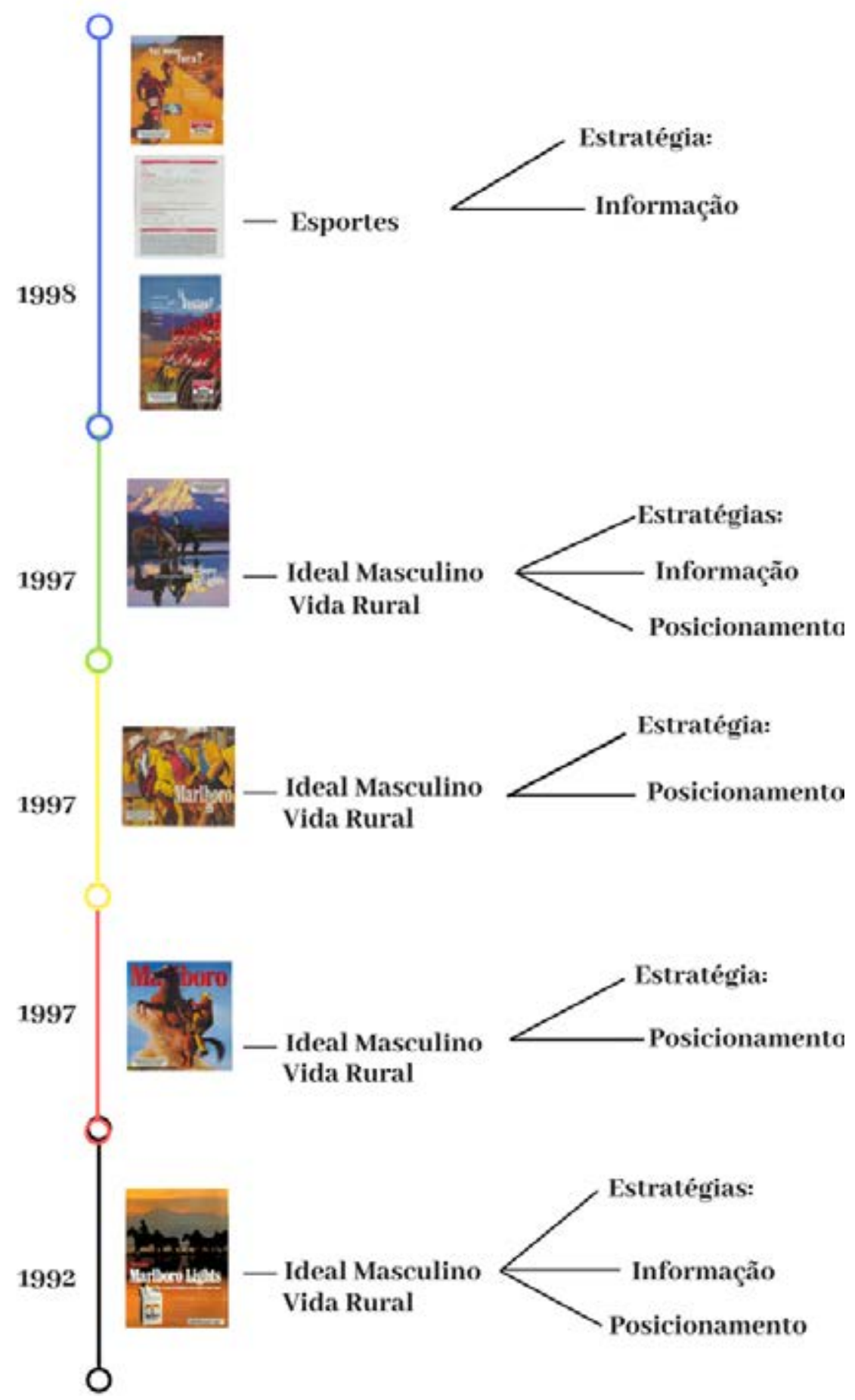




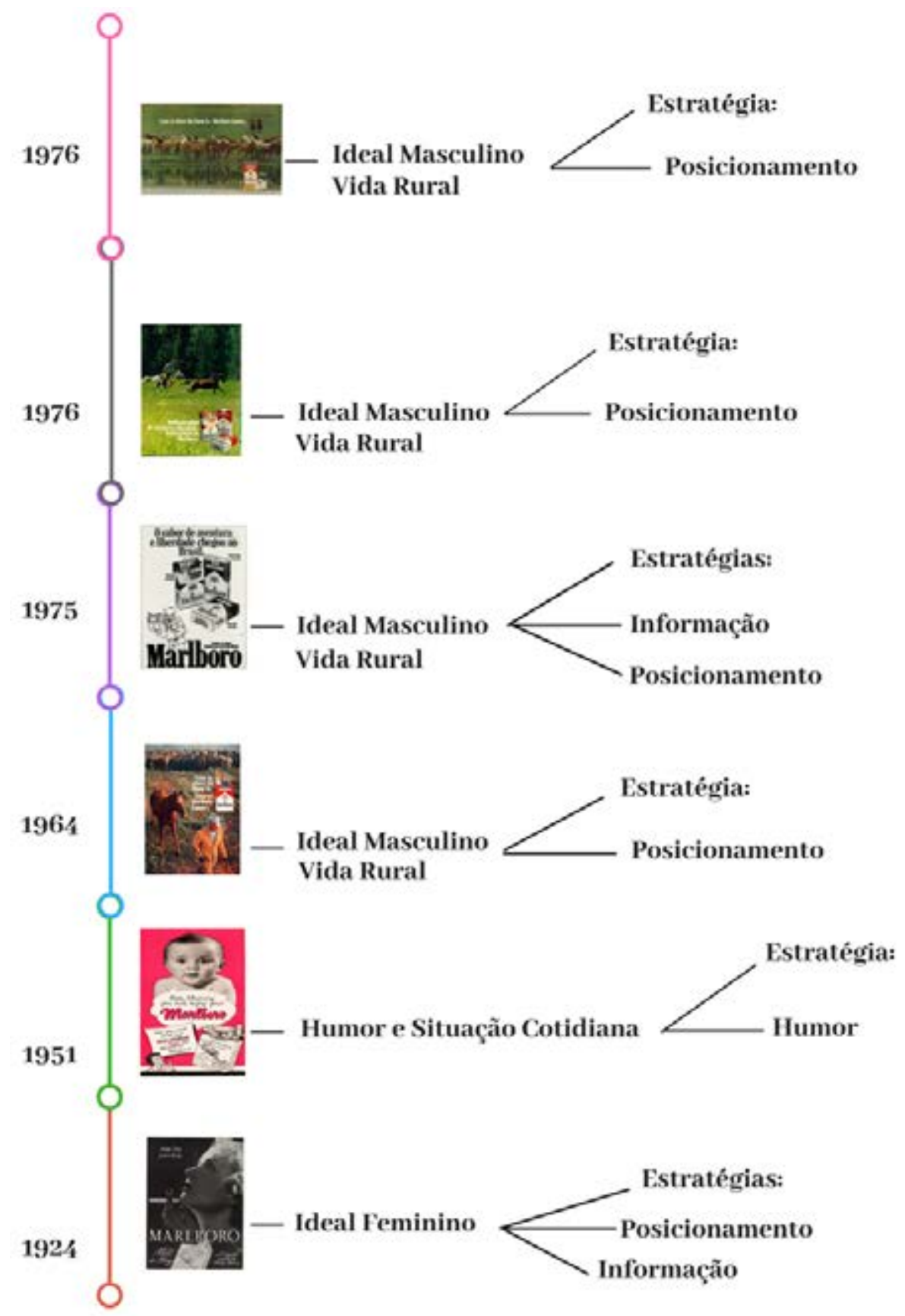

Fonte: Elaboração própria.

Para uma marca mundial de cigarros como a Marlboro, a evolução das estratégias de comunicação foi de suma importância, já que a concorrência entre as marcas tornou-se cada vez maior com sua expansão por diferentes mercados. Nesse sentido, a atualização da comunicação estratégica em seus vários aspectos torna-se necessária para fidelizar o cliente de forma eficiente. A partir do conceito de Tironi e Cavallo (2004) sobre a comunicação estratégi- 
ca, entende-se que a empresa necessita de planejamento além do seu momento atual, que envolva todo o contexto que rodeia a empresa e os diferentes fatores que podem influenciar. A escolha de estratégias e tipos de campanha depende do público-alvo, da época, do discurso que o anunciante quer adotar e dos valores que quer provocar, além dos meios utilizados na comunicação (TIRONI; CAVALLO, 2004). Todos esses fatores foram observados como relevantes no processo de mudanças que ocorreram nas campanhas de Marlboro.

O uso de diferentes estratégias e tipos de campanha relaciona-se com a/ a diversidade, citada por Perez (2012), de perspectivas e teorias presente no fenômeno comunicativo, pois apenas uma teoria não é suficiente para alcançar o objetivo final. Ao longo da comunicação da Marlboro, uma série de diversas estratégias e campanhas foi utilizada, porque a sociedade modificou-se e, com ela, modificaram-se as formas como a Marlboro se posicionava. Porém, houve um realinhamento com o intuito de persuadir cada vez mais o público conforme a marca passou a conhecê-lo melhor, e não por se preocupar com o bem da sociedade, já que as informações sobre os malefícios do cigarro começaram a ser divulgadas na sua embalagem por imposição e não por escolha. As transformações também mostram a capacidade de adaptação dessa marca aos diferentes contextos, talvez por isso seja um exemplo de empresa tão duradoura e com tantos adeptos pelo mundo todo.

Dentre os aspectos da Lei Antifumo que interferiram na campanha publicitária de cigarro, destacam-se:

- O maior grau de informação do público-alvo, pois, hoje, os consumidores possuem mais conhecimento por terem acesso a inúmeras informações sobre os danos que o consumo de tabaco causa;

- A inserção de imagens chocantes e desagradáveis, o completo oposto de imagens belas e agradáveis necessárias para persuadir o público;

- A dificuldade de apelo da própria embalagem, que teve que se adequar às normativas e, assim, ficou bastante equivalente às embalagens da concorrência;

- A busca por outras estratégias, menos explícitas, de publicidade.

Dessa forma, no contexto atual, em que as campanhas publicitárias de cigarro estão proibidas, uma solução encontrada pela marca foi adotar uma comunicação diferenciada em seu site. No meio online, a Marlboro faz uso de estratégias de informação, de posicionamento e de comparação ao incluir no discurso que a Philip Morris é a empresa líder no mercado internacional de tabaco e a segunda maior empresa de tabaco do Brasil. Há também certa contradição nas estratégias empregadas pela Marlboro em suas campanhas ao longo do tempo. As imagens e os temas quase sempre rivalizaram com os efeitos do próprio produto no consumidor: associação com crianças, com vida no campo, com esporte e, recentemente, com sustentabilidade em seu endereço 
eletrônico. Isso demonstra que a empresa sabe que trabalha com um produto polêmico e, de forma intencional e estratégica, coloca discursos ou apelos com valores positivos associados à marca, substituindo o foco no consumo do cigarro por outro mais socialmente amplo.

\section{Considerações finais}

A análise demonstrou as transformações ocorridas nas estratégias de comunicação da marca Marlboro e os tipos de campanha adotados no intervalo de tempo levantado, e o resultado evidenciou que a marca tabagista utilizouse de várias estratégias, principalmente a de posicionamento, para alcançar seus objetivos. Durante esse período, houve transformações em decorrência das mudanças do público-alvo ou pelas mudanças próprias do contexto social conforme a época. Também foram encontradas as estratégias de informação e de humor, porém em menor ocorrência. Já dentre os tipos de campanha, o mais utilizado foi o de propaganda, já que a maioria dos exemplares teve como objetivo a divulgação do produto, informando seus principais benefícios e atributos, além de utilizar o tipo de campanha para lançamento de produtos e campanha institucional.

Assim, para o objetivo específico de verificar as mudanças ocorridas nas campanhas publicitárias da marca Marlboro desde a década de 1924 até hoje, foi possível observar que a marca tabagista realizou quatro principais eixos de temas durante esse período: ideal feminino, humor e situação cotidiana, ideal masculino (estilo de vida rural) e esportes. Cada eixo foi direcionado para um público-alvo e veiculado em épocas diferentes, por exemplo, o eixo de humor e situação cotidiana tinha como público-alvo as mães e foi veiculado no período de 1951, já o eixo de ideal masculino e estilo de vida rural era direcionado para o público masculino, de forma geral, homens que viveram no campo ou se sentiam atraídos pelo estilo de vida rural, mesmo que habitassem a cidade.

Já para o objetivo específico de descrever quais aspectos da Lei Antifumo interferiram nas estratégias das campanhas publicitárias, foi constatado que, dentre as mudanças que a Lei Antifumo causou, a que mais interferiu nas estratégias das campanhas publicitárias foi a proibição da propaganda comercial tabagista. Após a regulamentação, os produtos deveriam ficar expostos no interior do estabelecimento comercial e $20 \%$ do mostruário visível ao público deveria ser ocupado por mensagens de advertências sobre os males do fumo, a proibição da venda a menores de 18 anos e a tabela de preços. Antes da regulamentação, era estabelecido que as embalagens deveriam conter advertências, porém em apenas uma das laterais do maço, carteira ou pacote; depois da regulamentação, ficou decidido que as embalagens devem conter mensagens de advertência em $100 \%$ da face posterior das embalagens e de uma de suas laterais, além de que, a partir de 2016, foi incluído texto de advertência adicional sobre os malefícios do fumo em $30 \%$ da parte frontal das 
A TRANSFORMAÇ̃̃O DA COMUNICAÇ̃̃O TABAGISTA:

UM ESTUDO DAS ESTRATÉGIAS DA MARCA MARLBORO

embalagens. Considerando o apelo de marca que a embalagem geralmente produz, essa mudança é significativa, já que limita inclusive a visualização da identidade visual da marca.

Para o objetivo específico de identificar quais as principais estratégias das campanhas publicitárias e os principais tipos de campanha utilizados pela marca, concluiu-se que a Marlboro fez uso especialmente da estratégia de posicionamento, presente em nove dos onze anúncios. Outra estratégia bastante presente foi a de informação, que consta em cinco exemplares, e por fim, a estratégia de humor utilizada em apenas uma peça. Já sobre os tipos de campanha, dentre os três tipos encontrados, o mais utilizado foi a de propaganda, em oito de onze exemplares; logo em seguida, a campanha de lançamento, presente em três anúncios; e a institucional, empregada apenas em dois.

Para pesquisas futuras sobre o tema, pretende-se conhecer mais sobre as estratégias atualmente exploradas pela marca em mídias sociais, já que mesmo com as restrições e exigências para se adequar ao período atual, a marca Marlboro continua líder mundial no mercado tabagista. Percebeu-se que a marca já busca saídas alternativas, fazendo com que o número de vendas aumente e o público-alvo seja alcançado, como por exemplo, por meio de alterações feitas no próprio site.

\section{Referências}

AGÊNCIA BRASIL. Tabagismo custa R\$ 56,9 bilhões por ano ao Brasil. 31/05/2017. Disponível em: <http:// agenciabrasil.ebc.com.br/geral/noticia/2017-05/tabagismo-custa-r-569-bilhoes-por-ano-ao-brasil>. Acesso em: 10 out. 2017

ANVISA. Publicada resolução que restringe aditivos em cigarros. 13/03/2012. Disponível em: <http:// portal.anvisa.gov.br/resultado-de-busca?p_p_id=101\&p_p_lifecycle=0\&p_p_state=maximized\&p_p_ mode=view\&p_p_col_id=column-1\&p_p_col_count=1\&_101_struts_action=\%2Fasset_publisher\%2Fview_ content\&_101_assetEntryld=2667724\&_101_type=content \&_101_groupld=219201\&_101_ urlTitle=publicada-resolucao-que-restringe-aditivos-em-cigarros\&inheritRedirect=true $>$. Acesso em: 19 out. 2017.

ARAUJO, Tarso. O futuro da indústria do tabaco. Revista Galileu, 2014. Disponível em: <http://revistagalileu. globo.com/Revista/Common/0,,ERT334296-17773,00.html>. Acesso em: 19 ago. 2017.

BARDIN, Laurence. Análise de Conteúdo. Lisboa, Portugal: Edições 70, 2009.

BARROSO, Luís Roberto. Liberdade de expressão, direito à informação e banimento da publicidade de cigarro. Revista Direito Adm., Rio de Janeiro, 224, p. 31-50, abr./jun. 2001. Disponível em: http:// bibliotecadigital.fgv.br/ojs/index.php/rda/article/viewFile/47757/45471. Acesso em: 20 fev. 2018.

BOEIRA, Sérgio Luís. Indústria de tabaco e cidadania: confronto entre redes organizacionais. Revista de Administração de Empresas, v. 46, n. 3, p.28-41, jul./set. 2006. Disponível em: http://www.scielo.br/ pdf/rae/v46n3/v46n3a04.pdf. Acesso em: 20 fev. 2018.

BONA, Rafael; BEAUMORD, Camila. O Cigarro e o Mito: um estudo sobre o Merchandising da marca Marlboro. In: INTERCOM, 11, 2010, Novo Hamburgo, RS. Anais... Novo Hamburgo: Feevale, 2010. Disponível em: <http://intercom.org.br/papers/regionais/sul2010/resumos/R20-0246-1.pdf>. Acesso em: 05 out. 2017.

BRUM, Analisa de Medeiros. Endomarketing. 2. ed. Porto Alegre: Ortiz, 1994. 
CABRAL, Plínio. Propaganda: técnica da comunicação industrial e comercial. São Paulo: Atlas, 1990.

CHANDLER JR., Alfred D. Strategy and Structure: Concepts in the History of the Industrial Enterprise. 2. ed. Cambridge: The M.I.T. Press, 1963. Disponível em: < https://ia800309.us.archive.org/31/items/ strategystructur00chan_0/strategystructur00chan_0.pdf>. Acesso em: 10 out. 2017.

FOLHA DE SÃO PAULO. Anvisa quer advertência direta em cigarro, como 'Você brocha'. 21/04/2017. Disponível em: <http://www1.folha.uol.com.br/equilibrioesaude/2017/04/1877374-anvisa-queradvertencia-direta-em-cigarro.shtml>. Acesso em: 28 set. 2017.

KOTLER, Philip; KELLER, Kevin Lane. Administração de marketing. 12. ed. São Paulo: Pearson Prentice Hall, 2006.

LIMA, Juliana de. Qual a relação entre o cigarro e o cinema. E como ela mudou ao longo dos anos. Nexo, 29/07/2017. Disponível em: <https://www.nexojornal.com.br/expresso/2017/07/29/Qual-arela\%C3\%A7\%C3\%A3o-entre-o-cigarro-e-o-cinema.-E-como-ela-mudou-ao-longo-dos-anos>. Acesso em: 29 set. 2017

LUPETTI, Marcélia. Planejamento de comunicação. 3. ed. São Paulo: Futura, 2002.

MUNDO DAS MARCAS. Cigarro. 2006. Disponível em: <http://mundodasmarcas.blogspot.com.br/2006/05/marlborocome-to-marlboro-country.html>. Acesso em 08 abril 2017.

OGDEN, James R.; CRESCITELLI, Edson. Comunicação integrada de marketing: Conceitos, técnicas e práticas. 2. ed. São Paulo: Prentice Hall, 2007.

OLIVEIRA, Ivone de Lourdes; PAULA, Carine F. O que é comunicação estratégica nas organizações? São Paulo: Paulus, 2007.

PÉREZ, Rafael Alberto. El estado del arte en la Comunicación Estratégica. Mediaciones Sociales, v. 1, n. 10, p. 121-196, 2012. Disponível em: <https://revistas.ucm.es/index.php/MESO/article/viewFile/39684/38179>. Acesso em: 20 nov. 2017

PROPAGANDAS históricas. Disponível em: <http://www.propagandashistoricas.com.br/search/label/cigarros?updatedmax=2014-03-17T15:30:00-03:00\&max-results=20\&start=20\&by-date=false $>$. Acesso em: 07 jun. 2017.

RENOVATO, Rogério Dias et al. Significados e sentidos de saúde socializados por artefatos culturais: leituras das imagens de advertência nos maços de cigarro. Ciência \& Saúde Coletiva, v. 14, n. 1, p. 15991608, 2009.

SAMPAIO, Rafael. Propaganda de Aa Z. 4. ed. Rio de Janeiro: Campus, 2013.

SANT'ANNA, Armando. Propaganda: teoria, técnica e prática. 8. ed. São Paulo: Cengage Learning, 2009.

TIRONI, Eugenio; CAVALLO, Ascanio. Comunicación Estratégica. Vivir en um mundo de senãles. Santiago, Chile: Aguilar Chilena, 2004

VASCONCELOS, Luciene Riccioti. Planejamento de Comunicação Integrada: Manual de sobrevivência para as organizações do século XX. São Paulo: Summus, 2009.

VIEIRA, Tereza Rodrigues; SÁVIO, Aderson José. Saúde do consumidor versus liberdade de expressão: questões sobre a publicidade do cigarro. Revista Cesumar, v. 6, n. 1, p. 117-131, jun. 2002.

YANAZE, Mitsuru Higushi. Relações Públicas e Marketing. In: KUNSCH, Margarida Maria Krohling. (Org). Obtendo resultados com relações públicas. 2. ed. São Paulo: Thomson Learning, 2006. 